\title{
Role of Lipoxygenase Products in Murine Pulmonary Granuloma Formation
}

\author{
Steven L. Kunkel, Stephen W. Chensue, \\ and Catharine Mouton \\ Department of Pathology, University of Michigan Medical \\ School, University of Michigan, Ann Arbor, Michigan 48109 \\ Gene I. Higashi \\ Department of Epidemiology, School of Public Health, University \\ of Michigan, Ann Arbor, Michigan 48109
}

bstract. Various arachidonic acid (AA) metabolites are known to regulate immune cell function(s) and dictate the progression of both acute and chronic inflammatory reactions. Using a model of Schistosoma mansoni egg-induced hypersensitivity granulomas, we have delineated the in vivo effects of inhibitors of cyclooxygenase (CO) and lipoxygenase (LO) pathways on granuloma development and granuloma macrophage I-region-associated (Ia) antigen expression. In addition, by high performance liquid chromatography (HPLC) we have profiled the metabolism of AA by macrophages that are isolated from granulomatous foci, and have biochemically characterized the in vitro specificity and activity of selected CO and LO inhibitors. The development of hypersensitivity-type pulmonary granulomas in mice was dramatically suppressed by inhibitors with anti-LO activity (nordihydroguairetic acid (NDGA), nafazatrom, and BW755c) in a dose-dependent manner, while indomethacin, which is primarily CO-selective, had no significant effect. Furthermore, NDGA and nafazatrom profoundly arrested the normal progression of preformed granulomatous lesions. The inhibitors of the LO pathway also suppressed the in vivo kinetics of Ia antigen expression by granuloma macrophages. In contrast, indomethacin augmented Ia-antigen expression. The major AA metabolites that were synthesized by the granuloma macrophages were shown to be leukotriene $\mathrm{C}_{4}$ and mono-hydroxyeicosatetraenoic acids. HPLC analysis of AA metabolites from granuloma macrophages that were treated with the various inhibitors confirmed that indomethacin

Received for publication 19 September 1983 and in revised form 26 March 1984.

J. Clin. Invest.

(c) The American Society for Clinical Investigation, Inc.

$0021-9738 / 84 / 08 / 0514 / 11 \quad \$ 1.00$

Volume 74, August 1984, 514-524 was most CO-selective and NDGA most LO-selective. Nafazatrom and BW755c inhibited AA metabolism by both pathways. Notably, high concentrations of the compounds $\left(5 \times 10^{-5} \mathrm{M}\right)$ tended to suppress all products. Our results suggest that LO products may be important in the generation and maintenance of immune granulomatous inflammatory responses.

\section{Introduction}

The metabolism of arachidonic acid (AA) ${ }^{1}$ by inflammatory cells is known to involve a cascade of complex biochemical reactions that result in the production of numerous biologically active lipids, including: thromboxanes, prostaglandins (PGs), hydroxyeicosatetraenoic acids (HETEs), hydroperoxyeicosatetraenoic acids (HPETEs), and leukotrienes (LTs) (1). These metabolites from both the cyclooxygenase (CO) and lipoxygenase (LO) pathways are known to strongly influence immune cell function (2-6), as well as modulate the progression of inflammatory reactions (7-10). Although AA derivatives can be found at inflammatory foci (11), their specific contribution to inflammatory events is not fully established. Thus, many investigators have focused on the biochemical manipulation of AA metabolism (12-14) in order to elucidate the inflammatory role of AA metabolites and to pharmacologically control inflammatory reactions (15-18). In various in vivo and in vitro models, AA metabolic inhibitors have been shown to modulate both acute inflammatory cell function (19-21) and T cell-mediated responses (22-25). Furthermore, recent evidence suggests that AA products of the LO pathway may play a primary role in promoting inflammatory reactions $(1,3,4)$. Therefore, new ther-

1. Abbreviations used in this paper: $\mathrm{AA}$, arachidonic acid; $\mathrm{CO}$, cyclooxygenase; FBS, fetal bovine serum; HPLC, high performance liquid chromatography; HPETEs, hydroperoxyeicosatetraenoic acids; HETEs, hydroxyeicosatetraenoic acids; $\mathrm{LT}$, leukotrienes; $\mathrm{LTB}_{4}, \mathrm{LTC}_{4}, \mathrm{LTD}_{4}$, leukotrienes $B_{4}, C_{4}$, and $D_{4}$; NDGA, nordihydroguairetic acid; PG, prostaglandin; $\mathrm{PGD}_{2}, \mathrm{PGE}_{2}, \mathrm{PGF}_{2 \alpha}$, prostaglandins $\mathrm{D}_{2}, \mathrm{E}_{2}$, and $\mathrm{F}_{2 \alpha}$; Ia, I-region-associated membrane. 
apeutic agents with anti-LO activity may be more effective in treating inflammatory diseases than the commonly used drugs with mainly anti-CO activity.

In the present study we wished to establish the contribution of the AA metabolic pathways to the formation of chronic hypersensitivity granulomas. To this end, we used a well-described model of experimental murine hypersensitivity pulmonary granuloma formation by embolization of Schistosoma mansoni eggs (26). We evaluated several compounds that have differential inhibitory effects on AA metabolism via the $\mathrm{CO}$ or $\mathrm{LO}$ pathways with regard to their effect in vivo on granuloma formation and granuloma macrophage I-region-associated membrane (Ia) antigen expression. We also utilized high performance liquid chromatography (HPLC) to analyze the spectrum of AA metabolites that was produced by macrophages that were isolated from the granulomas, and determined the in vitro selectivity of the various inhibitory compounds on granuloma macrophage AA metabolism. Our results demonstrated that compounds with potent anti-LO activity (nordihydroguairetic acid (NDGA), nafazatrom, and BW755c) profoundly suppressed hypersensitivity granuloma formation and granuloma macrophage Ia-antigen expression. In contrast, the highest nontoxic dose of the $\mathrm{CO}$ inhibitor, indomethacin, had no effect on granuloma formation and appeared to augment Ia-antigen expression. Furthermore, the AA metabolites that were synthesized by granuloma macrophages were primarily LO derivatives, which included $\mathrm{LTC}_{4}, \mathrm{LTD}_{4}, 5$-HETE, and 12-HETE. Thus, LO products may be important in granuloma formation, and the use of LO inhibitors may provide a viable approach to manipulating some forms of chronic inflammation.

\section{Methods}

Animals. Female CBA/J mice (The Jackson Laboratory, Bar Harbor, ME) were used throughout this study. The mice were maintained under standard care and given food and water ad libitum.

Schistosome egg isolation and induction of pulmonary egg granulomas. Eggs were isolated from the livers of mice previously that were infected with 200 cercariae of $S$. mansoni by the method of Coker and von Lichtenberg (27). The isolated schistosome eggs were suspended to $4,000 / \mathrm{ml}$ sterile physiological saline and each mouse received 2,000 eggs via tail vein injection.

Administration of AA metabolic inhibitors. Various inhibitors of AA metabolism were examined for their ability to modulate pulmonary granuloma development. Indomethacin and NDGA (Sigma Chemical Co., St. Louis, MO) nafazatrom (Miles Laboratory, Elkhart, IN), and BW755c (Wellcome Research Laboratories, Beckenham, England) were prepared fresh daily as follows: solutions of indomethacin, nafazatrom, and NDGA were initially prepared at 8,20 , and $20 \mathrm{mg} / \mathrm{ml}$, respectively, in $0.1 \mathrm{~N} \mathrm{NaOH}$. Before injection, indomethacin was diluted to $400 \mu \mathrm{g} /$ $\mathrm{ml}$ in pyrogen-free saline, and NDGA and nafazatrom was diluted to $2 \mathrm{mg} / \mathrm{ml}$ saline. BW755c was prepared at $4 \mathrm{mg} / \mathrm{ml}$ in saline. Animals received daily intraperitoneal injections of the appropriate volume of inhibitor after egg embolization. Control animals were given injections of diluent alone.

Determination of pulmonary granuloma area. Mice were killed at 4,8 , and $16 \mathrm{~d}$ postegg challenge and the lungs were inflated with $10 \%$ buffered formalin, removed, prepared for histologic section, and stained with hematoxylin and eosin. The pulmonary granuloma areas were measured from sections using an Omicron alpha image analyzer (Bausch and Lomb Inc., Rochester, NY) with data being fed into an attached computer. A minimum of 20 granulomas were measured from each lung. Granulomas were measured from at least five mice per data point.

Determination of macrophage Ia antigen expression. Granuloma macrophages from treated and nontreated mice were isolated as described below, cultured for $\mathbf{4 h}$ in glass tissue culture chambers (Lab-Tek Div., Miles Laboratories Inc., Naperville, IL), and washed extensively to remove nonadherent cells. The monolayers were then washed with phosphatebuffered saline (PBS)-2\% fetal bovine serum (FBS)-0.2\% azide, fixed with $1 \%$ paraformaldehyde, and a sandwich-staining method was employed, which used monoclonal antibody that was directed to $\mathrm{I}-\mathrm{A}^{\mathrm{k}}(28)$. Monoclonal anti-I-A $A^{b}$ was employed as a control (29). After 45 min incubation with the monoclonal antibody, the slides were washed with PBS- $2 \%$ FBS- $0.2 \%$ azide and treated with fluorescein-conjugated $F\left(a^{\prime}\right)_{2}$ rabbit anti-mouse IgG (Cappel Laboratories Inc., Cochranville, PA). After rinsing, a minimum of 200 cells were counted by ultraviolet microscopy to determine the proportion of stained cells. This protocol has been extensively used to examine various macrophage populations with respect to la antigen expression (30).

Isolation and culture of granuloma macrophages. Dispersed granuloma cells were obtained from schistosome egg-induced lung granulomas by a modification of the procedure of Moore, Grove, and Warren (31). Briefly, at 4,8 , or $16 \mathrm{~d}$ postembolization, mice were killed and the granulomatous lungs were perfused with cold RPMI-1640 (Gibco Laboratories, Grand Island, NY) to remove blood from the vasculature. The lungs were then inflated with $1 \mathrm{ml}$ ice-cold RPMI-1640, excised, and homogenized for $20 \mathrm{~s}$ at low speed in a commercial Waring blender. Granulomas were collected and rinsed free of single cells over a sterile, stainless steel mesh. Granulomas were then washed three times in RPMI, pelleted in a 50-ml plastic centrifuge tube, and resuspended in $3 \mathrm{vol}$ of sterile digestion medium which consisted of RPMI-1640 that contained $10 \mathrm{mM}$ Hepes, $2,000 \mathrm{U} / \mathrm{ml}$ type II collagenase (Sigma Chemical Co.), and $20 \mu \mathrm{g} / \mathrm{ml}$ gentamicin (Schering Corp., Kenilworth, NJ). The dispersed cells were vigorously agitated for $30 \mathrm{~min}$ in a $37^{\circ} \mathrm{C}$ water bath. The suspension was passed through a No. 100 steel mesh and collected by centrifugation. The resuspended cells were strained through a $50-\mu \mathrm{m}$ nylon sieve to remove nondispersed cells and parasite eggs. Granuloma cells were washed twice, centrifuged, counted, and resuspended in RPMI which contained 10\% FBS (KC Biological, Inc., Lenexa, KS) and 20 $\mu \mathrm{g} / \mathrm{ml}$ gentamicin (complete media). Granuloma macrophages, suspended to $1 \times 10^{6}$ cells $/ \mathrm{ml}$, were allowed to adhere for $4 \mathrm{~h}$ at $37^{\circ} \mathrm{C}$ in a $5 \% \mathrm{CO}_{2}$, humidified atmosphere in glass tissue culture chambers or on $60-\mathrm{mm}$ plastic tissue culture plates (Lab-Tek, Miles Laboratories Inc.). Nonadherent cells were removed by at least two vigorous rinses with warm, serum-free medium. The number of adherent cells was quantitated by direct counting of Wright stained monolayers. These cells are routinely $>90 \%$ macrophages based on morphological criteria, phagocytosis of inert beads, and staining for nonspecific esterase (32).

Determination of $\mathrm{CO}$-mediated $\mathrm{AA}$ metabolites. The washed macrophage monolayers (60-mm dishes) were overlaid with $2.0 \mathrm{ml}$ of serumfree RPMI which contained $1 \mu \mathrm{Ci}$ of $\left[{ }^{3} \mathrm{H}\right] \mathrm{AA}$ (New England Nuclear, Boston, MA, $91 \mathrm{Ci} / \mathrm{mmol} \mathrm{sp}$ act). After incubating overnight (14 h) at $37^{\circ} \mathrm{C}$, the media were collected and the AA metabolites were extracted as follows: Media were collected after incubation, acidified to $\mathrm{pH} 3.0$ with $1 \mathrm{~N} \mathrm{HCl}$, then extracted twice with 3 vol of ethyl acetate. The solvent was vaporized under vacuum using a Speed Vac concentrator (Savant Instruments, Inc., Hicksville, NY). Extracts were stored under 
$100 \% \mathrm{~N}_{2}$ at $-20^{\circ} \mathrm{C}$, then were dissolved in $0.1 \mathrm{ml}$ absolute methanol just before column chromatography. Metabolites of [ $\left.{ }^{3} \mathrm{H}\right] \mathrm{AA}$ were identified by reverse-phase HPLC using a modified method of Van Rollins et al. (33). One-tenth milliliter samples were applied to a 5- $\mu \mathrm{m} \mathrm{C-18}$ reverse phase $(30 \times 0.4 \mathrm{~cm})$ column (Varian Associates, Inc., Palo Alto, CA) at $29^{\circ} \mathrm{C}$ with a $1 \mathrm{ml} / \mathrm{min}$ flow rate. The solvent, acetonitrile (Burdick \& Jackson Laboratories Inc., Muskegon, MI)/water/trifluoracetic acid (pH 2.0) (Pierce Chemical Co., Rockford, IL) was used as follows: The first $40 \mathrm{~min}$ were isocratic (31:69:0.1, vol/vol/vol), and were followed by a linear gradient increase of acetonitrile which started at 45:55:0.165:35:0.1 over a $2-\mathrm{h}$ period. Finally, the column was washed $30 \mathrm{~min}$ at 100:0:0.1. The eluate was continuously monitored for ultraviolet absorbance (for internal standards: $210 \mathrm{~nm}$ for CO products, $280 \mathrm{~nm}$ for LTs, and $235 \mathrm{~nm}$ for mono-HETEs) and radioactivity. The latter was measured with an in-line radioactive monitor (Radiomatic Instruments \& Chemical Co. Inc., Tampa, FL), and a flow ratio of 5:1 (aqueous scintillant to sample) was used. All data were computed using an inline 402 microprocessor (Varian Associates Inc.), which calculated the percentage of recovered metabolites by integrating the HPLC elution profiles. To aid in the verification of specific LO products, especially $\mathrm{LTC}_{4}$, the following isocratic solvent system described by Rouzer et al. (34) was occasionally used: 65:34.9:0.1 (methanol/water/acetic acid pH 5.0). Using this solvent system and reverse-phase HPLC, LTC $_{4}$ was found to coelute with labeled and unlabeled $\mathrm{LTC}_{4}$ between 20 and 24 min (scans not shown). Characteristic ultraviolet spectra of $\mathrm{LTC}_{4}$ and mono-HETEs was monitored using a Cary 210 spectrophotometer (Varian Associates, Inc.) and compared with known standards.

The column was calibrated using radiolabeled and unlabeled standards. Thromboxane $\mathrm{B}_{2}, \mathrm{PGE}_{2}, \mathrm{PGF}_{2 \alpha}$, and $\mathrm{PGD}_{2}$, as well as 5- and 12-HETE, were kindly provided by Drs. John Pike and Robert Gorman (Upjohn Co., Kalamazoo, MI). ${ }^{14} \mathrm{C}$-labeled $\mathrm{LTB}_{4}$ was provided by Henry Showell (Pfizer Central Research, Groton, CT) $\left[{ }^{3} \mathrm{H}\right] \mathrm{LTC}{ }_{4}$ and $\left[{ }^{3} \mathrm{H}\right] \mathrm{AA}$ were purchased from New England Nuclear. Unlabeled LTs were provided by Dr. J. Rokach (Merck Frosst Laboratories, Quebec, Canada). 15-HPETE and 15-HETE were prepared using soybean lipoxygenase (Sigma Chemical Co.) as previously described (35), and were isolated by reverse-phase HPLC by the method of Bailey et al. (2). In some cases, unlabeled standards were added to samples to act as internal markers. In addition, gas chromatograph/mass spectroscopy was conducted on nonlabeled $\mathrm{PGE}_{2}$ and nonlabeled mono-HETEs to verify the compounds as true standards.

In vitro specificity and activity of $A A$ metabolic inhibitors. Two million granuloma macrophages in $2 \mathrm{ml}$ of complete media were added to 60 $\mathrm{mm}$ diameter culture dishes and were incubated for $4 \mathrm{~h}$ at $37^{\circ} \mathrm{C}$ in $5 \%$
$\mathrm{CO}_{2} / 95 \%$ air. Nonadherent cells were removed by washing with warm serum-free media. Indomethacin, NDGA, nafazatrom, and BW755c were prepared as 5-mM stock solutions in absolute ethanol. The working stock solutions were diluted in serum-free media to a final concentration of either 5 or $50 \mu \mathrm{M}$. The washed macrophages were overlaid with 2 $\mathrm{ml}$ of media/inhibitor solution which contained $1 \mu \mathrm{Ci}$ of $\left[{ }^{3} \mathrm{H}\right] \mathrm{AA}$. After incubating overnight $(14 \mathrm{~h})$ at $37^{\circ} \mathrm{C}$, the media was collected and the AA metabolites were extracted, as described above, and the AA metabolites were characterized by HPLC analysis. The number of adherent cells after inhibitor treatment was quantitated by counting Wright stained monolayers, and the macrophages were identified by the specific criteria outlined above. Viability of the cultured macrophages was not altered with the inhibitor treatment when compared with controls, as assessed by trypan blue exclusion and analysis of supernatant for the release of the cytoplasmic marker enzyme, lactic dehydrogenase. The number of viable, adherent macrophages per dish was identical among both groups. In addition, the inhibitors did not influence the uptake of $\left[{ }^{3} \mathrm{H}\right] \mathrm{AA}$, as compared with control macrophages.

Statistical analysis. The $t$ test was used to analyze control and experimental groups throughout the studies. Values of $P>0.05$ were not considered significant.

\section{Results}

Modulation of pulmonary granuloma formation by inhibitors of AA metabolism. Pulmonary granuloma development around the embolized schistosome egg was modulated by inhibitors of AA metabolism in a dose-dependent fashion (Fig. 1). By examining granuloma size at $8 \mathrm{~d}$ post-challenge, the in vivo doseresponse activity of the various $\mathrm{AA}$ inhibitors was characterized. Indomethacin showed a trend of augmentation at $5 \mathrm{mg} / \mathrm{kg}$, and has no effect at $2.5 \mathrm{mg} / \mathrm{kg}$. The highest dose of indomethacin $(10 \mathrm{mg} / \mathrm{kg})$ proved to be toxic, but in surviving animals suppression could be demonstrated. Nafazatrom and NDGA proved to be very potent in suppressing granuloma development at 10 $\mathrm{mg} / \mathrm{kg}$, while BW755c significantly affected the granulomatous reaction only at 25 and $50 \mathrm{mg} / \mathrm{kg}$. The $50 \%$ suppressive dose (from Fig. 1) was used to examine the effect of the inhibitors on the kinetics of granuloma developed at 4-, 8-, and 16-d postgranulomagenic challenge. Pulmonary granuloma formation around the embolized schistosome eggs was shown to increase linearly over the 16-d study period (Fig. 2). Granulomas were
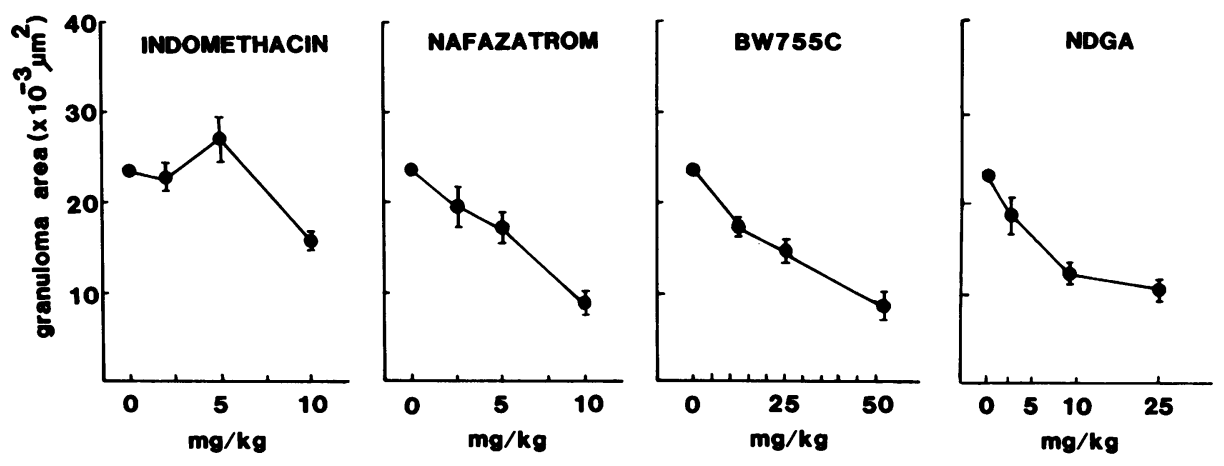

Figure 1. Dose-response effect of inhibitors of AA metabolism on the development of $S$. mansoni egg-induced pulmonary granulomas. Points represent the mean granuloma area \pm SEM, 5-7 mice per point. 


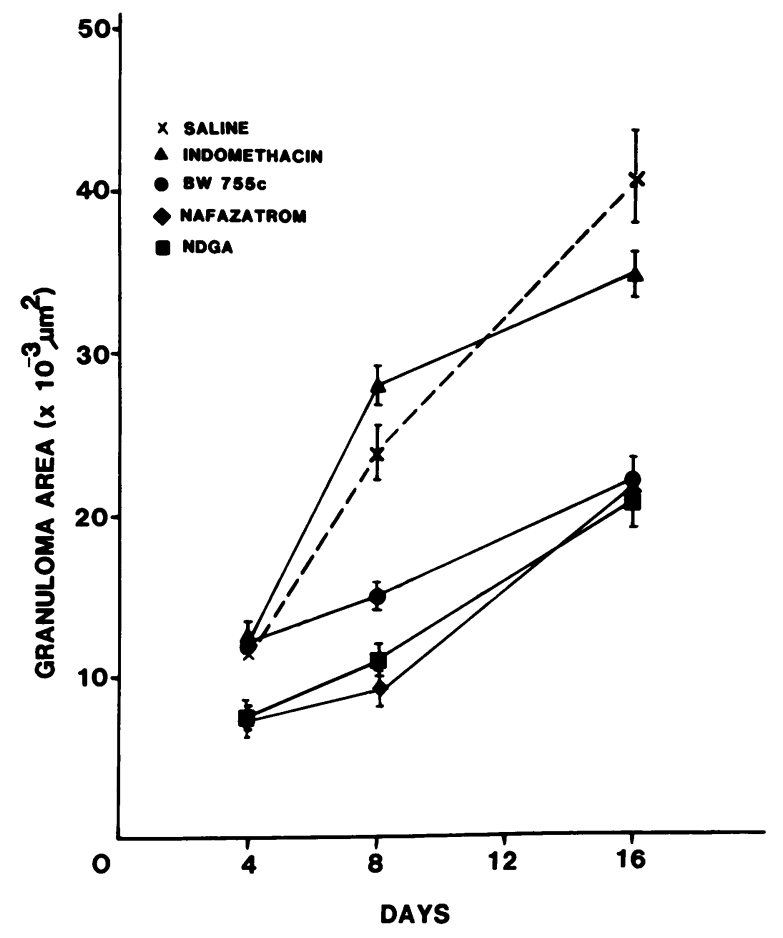

Figure 2. Effect of daily treatment with inhibitors of AA metabolism on the kinetics of $S$. mansoni egg-induced granuloma development. Points represent the mean granuloma area \pm SEM, 5-7 mice per group.

not significantly affected in those animals that received $5 \mathrm{mg} /$ $\mathrm{kg}$ indomethacin from the day of challenge. In contrast, granuloma formation in animals that were treated with NDGA $(25$ $\mathrm{mg} / \mathrm{kg}$ ) or nafazatrom $(10 \mathrm{mg} / \mathrm{kg}$ ) was dramatically suppressed at each of the time points examined. Likewise, BW755c (50 $\mathrm{mg} / \mathrm{kg}$ ) inhibited the development of granulomas at days 8 and 16 (Fig. 2). By day 16 of postgranulomagenic challenge, all compounds with anti-LO activity suppressed the normal granulomatous response by $\sim 50 \%$. Fig. 3 shows the histologic appearance of representative lesions from the treated and control groups at $16 \mathrm{~d}$.

Modulation of granuloma macrophage Ia antigen expression by inhibitors of $A A$ metabolism. The ability of macrophages to express Ia antigens is a strict requirement for macrophage-mediated antigen presentation to $\mathrm{T}$ cells, and is probably related to the state of macrophage maturation (36). Furthermore, such macrophage- $T$ cell interactions are thought to occur at hypersensitivity granuloma foci (37). Since AA metabolites appear to be involved in the regulation of Ia antigen expression by macrophages $(38,39)$, it was important to examine the effect of inhibitors of AA metabolism on the kinetics of macrophage Ia antigen expression in synchronously developing hypersensitivity lesions. As shown in Fig. 4, in control group the percentage of granuloma macrophages expressing Ia antigens in- creased to $55 \%$ over the 16 -d study period. The increase in Iapositive granuloma macrophages coincides with the increase in the degree of the cellular infiltration (Fig. 2). The kinetics of granuloma macrophage Ia antigen expression was significantly altered by the various inhibitors of AA metabolism. In those animals receiving indomethacin, the percentage of Ia-positive macrophages from the granulomas was increased at each of the time points that was examined (Fig. 4). At days 4, 8, and 16, the percentage of Ia-positive granuloma macrophages was augmented by 48,30 , and $17 \%$, respectively. This is in contrast with the percentage of Ia-positive macrophages that were isolated from animals treated with either BW755c, NDGA, or nafazatrom. These three compounds, which had anti-LO activity, were shown to suppress granuloma macrophage Ia antigen expression at 8 and $16 \mathrm{~d}$ post-challenge. By day 16 , the percentage of Iapositive granuloma macrophages from the animals that were treated with these inhibitors was suppressed by as much as $60 \%$. Interestingly, the decrease in granuloma macrophage Ia antigen expression paralleled the decrease in granuloma size that was observed after treatment with these compounds.

Effect of inhibitors of $A A$ metabolism on established granuloma formation. Since treatment with the various inhibitors of AA metabolism from day of egg challenge was shown to modulate hypersensitivity granuloma development and regulate the expression of Ia antigens by granuloma macrophages, it was important to determine if inhibitor treatment could affect ongoing hypersensitivity lesions. Thus, granulomas were allowed to develop for $\mathbf{8 d}$, at which point daily inhibitor treatment was initiated and continued until exsanguination at day 16. As demonstrated in Fig. 5, treatment with those compounds that suppressed the LO pathway arrested or reduced further granuloma development. In contrast, indomethacin treatment that was initiated at day 8 did not statistically alter the developing granulomas. NDGA was found to be the most effective compound in suppressing the progression of established lesions. Examination of granuloma macrophages from these suppressed lesions also revealed reduced Ia antigen expression (data not shown).

Identification of $A A$ metabolites by granuloma macrophages. The AA metabolites spontaneously released by granuloma macrophages that were isolated from synchronously developing hypersensitivity lesions were determined by HPLC analysis. Two major radiolabeled peaks in addition to a number of smaller peaks were obtained. A representative profile is shown in Fig. 6 (HPLC analysis was conducted on three separate sets of experiments). The first significant radioactive peak (34-36 min) represented $\sim 11 \%$ of the recovered radioactive material and was found to coelute with $\mathrm{PGE}_{2}$. The first major radioactive peak possessed a retention time of 50-52 min and had a retention time that was identical to $\left[{ }^{3} \mathrm{H}\right] \mathrm{LTC}_{4}$ and nonlabeled $\mathrm{LTC}_{4}$. This peak represented $33 \%$ of the total radiolabeled AA metabolites. The other major peak eluted at 84-86 min and eluted with the retention time of 5-HETE; this mono-HETE constituted $20 \%$ of the AA metabolites. Additional radiolabeled peaks that were observed at 68-70 $\mathrm{min}\left(\mathrm{LTD}_{4}\right)$ and $98-101 \mathrm{~min}$ (12-HETE) 

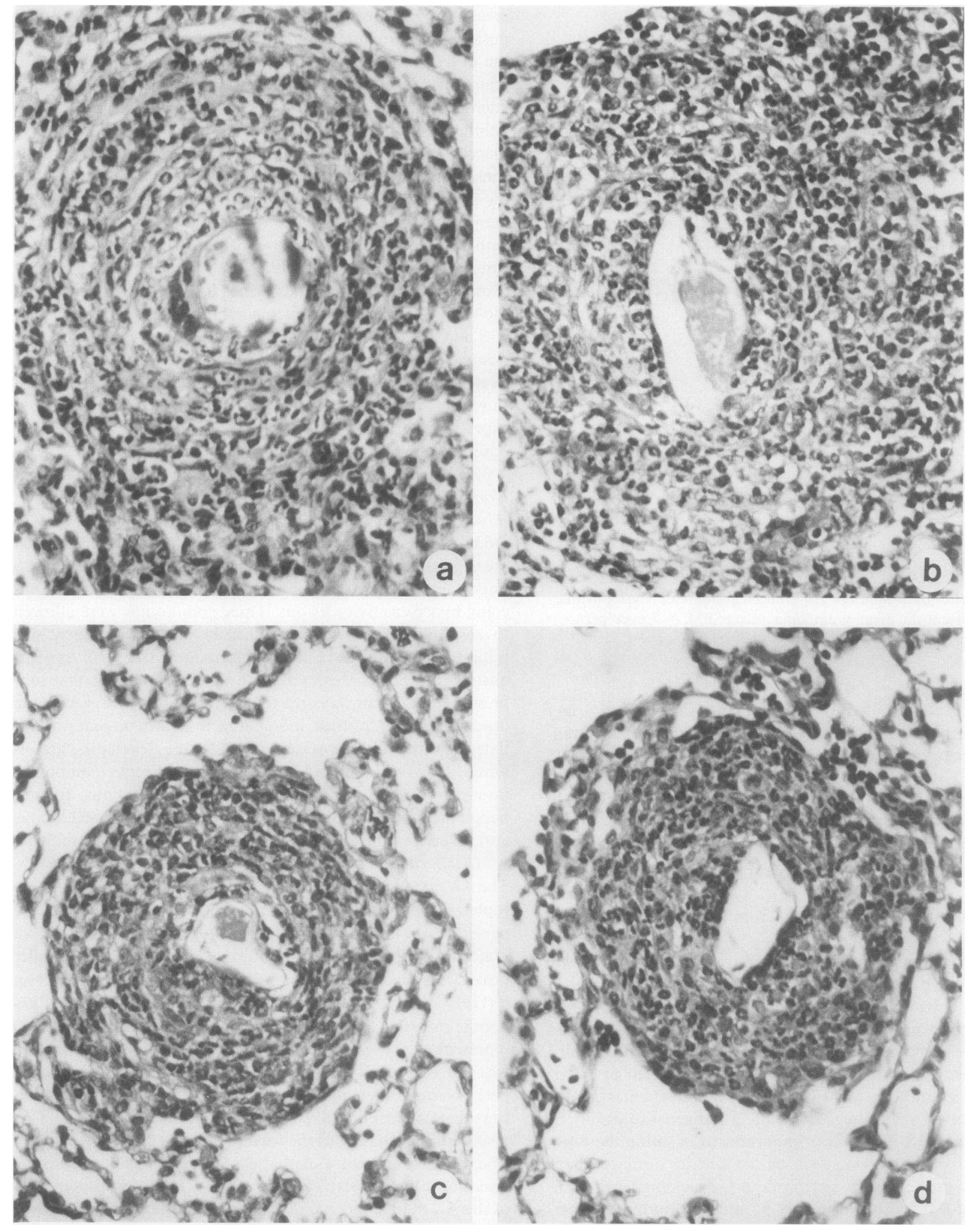


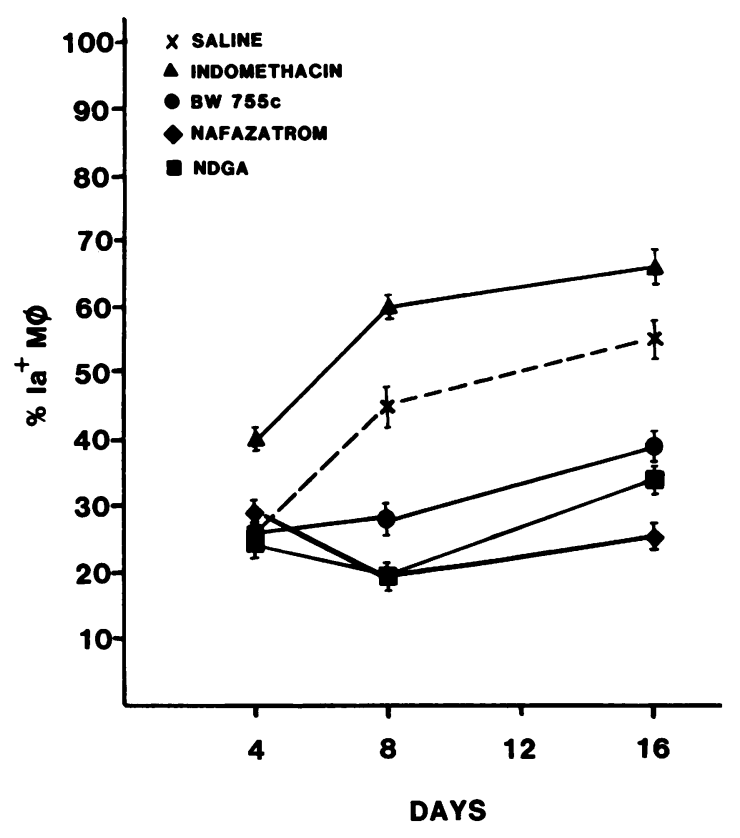

Figure 4. Effects of daily treatment with AA inhibitors on the kinetics of schistosome egg granuloma macrophage la antigen expression. Points represent the mean \pm SEM, 5-7 mice per group.

represented 12 and $9 \%$ of the total recovered radioactivity, respectively. The radioactive peak that eluted at $92 \mathrm{~min}$ was not identified, but most likely represents an additional mono-HETE, since all mono-HETE eluted from the column between 80 and 110 min using the described solvent conditions (28). The ultraviolet spectra of extracts from pooled granuloma macrophage preparations, which eluted from the HPLC at 48-54 and 82$88 \mathrm{~min}$, are shown in Fig. 7, $A$ and $B$, respectively. The ultraviolet spectrum of the material which eluted from the reverse-phase HPLC at 48-54 min possessed an absorbance maximum of 280 $\mathrm{nm}$, with smaller absorbances at 292 and $270 \mathrm{~nm}$; this profile is characteristic of $\mathrm{LTC}_{4}(40)$. In addition, Fig. $7 \mathrm{~B}$ shows the ultraviolet spectrum of the material that eluted at $82-88 \mathrm{~min}$. This spectrum showed a single absorbance peak at $235 \mathrm{~nm}$, which is characteristic for mono-HETEs (4). The above data demonstrate that granuloma macrophages are capable of synthesizing a variety of AA metabolites that consist primarily of LO derivatives.

Specificity and activity of $\mathrm{CO}$ and LO inhibitors on granuloma macrophage AA metabolism. Having determined the effects of the various AA metabolic inhibitors on granuloma formation in vivo, it was important to establish their relative specificity and activity on granuloma macrophages AA metabolism in vitro. Isolated granuloma macrophages were supplied with

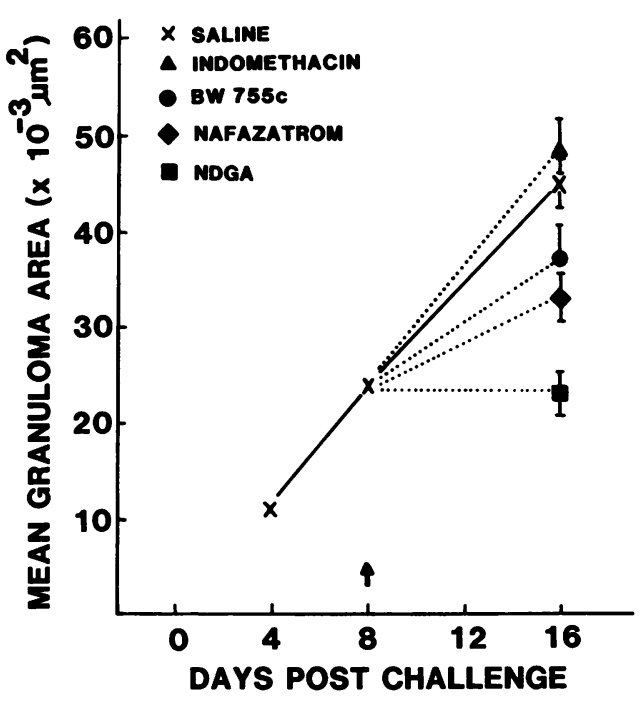

Figure 5. Effect of treatment with inhibitors of AA metabolism on established schistosome egg granuloma formation. Inhibitor treatment was initiated on day 8 and continued until day 16 . The following dose schedule was used daily from day 8 : indomethacin, $5 \mathrm{mg} / \mathrm{kg}$; BW755c, $50 \mathrm{mg} / \mathrm{kg}$; nafazatrom, $10 \mathrm{mg} / \mathrm{kg}$; and NDGA, $10 \mathrm{mg} / \mathrm{kg}$. Points represent the mean granuloma area \pm SEM, 5-7 mice per group.

$\left[{ }^{3} \mathrm{H}\right] \mathrm{AA}$ as described above and the integrated HPLC elution profiles of treated and untreated cultures were compared. The characteristic pattern of control cultures was substantially altered upon treatment with $\mathrm{CO}$ and LO inhibitors. As shown in Fig. 8 , indomethacin at $5 \mu \mathrm{M}$ reduced the synthesis of $\mathrm{PGE}_{2}$ by $\sim 90 \%$. Interestingly, at $5 \mu \mathrm{M}$, indomethacin appeared to accentuate the production of mono-HETEs, while at the higher dose all LO products were partially suppressed and $\mathrm{CO}$ products were virtually eliminated. At both 5 and $50 \mu \mathrm{M}$, BW755c suppressed the production of both $\mathrm{CO}$ and $\mathrm{LO}$ products. BW755c inhibited $\mathrm{PGE}_{2}$ and $\mathrm{LT}$ production by $75 \%$ at $5 \mu \mathrm{M}$ and $90 \%$ at $50 \mu \mathrm{M}$ (Fig. 9). Comparatively, the formation of mono-HETEs was less sensitive to BW755c, since 5 and $50 \mu \mathrm{M}$ resulted in a 22 and $64 \%$ reduction in mono-HETE synthesis, respectively. At $5 \mu \mathrm{M}$, NDGA was the most selective LO inhibitor, as shown in Fig. 10, where both LT and mono-HETE synthesis were suppressed by 66 and $40 \%$, while $\mathrm{PGE}_{2}$ production was not inhibited. The $50-\mu \mathrm{M}$ concentration of NDGA further suppressed the formation of $\mathrm{LO}$ products, but also decreased $\mathrm{PGE}_{2}$ synthesis by $30 \%$. The suppression profile of AA metabolites by nafazatrom was very similar to that of BW755c, and reduced both $\mathrm{PGE}_{2}$ and $\mathrm{LO}$ products at 5 and $50 \mu \mathrm{M}$. Specifically, at $5 \mu \mathrm{M}, \mathrm{PGE}_{2}, \mathrm{LT}$, and mono-HETE production were suppressed by 35,62 , and $14 \%$, respectively (Fig. 11). A greater reduction
Figure 3. Photomicrographic appearance of 16-d pulmonary granulomas around schistosome eggs in mice treated with ID $_{50}$ doses of $\mathrm{AA}$ metabolic inhibitors. (a) Normal (control) granuloma development; (b) indomethacin $(5 \mathrm{mg} / \mathrm{kg}) ;(c)$ nafazatrom $(10 \mathrm{mg} / \mathrm{kg})$; and $(d)$ BW755c $(50 \mathrm{mg} / \mathrm{kg})$. 


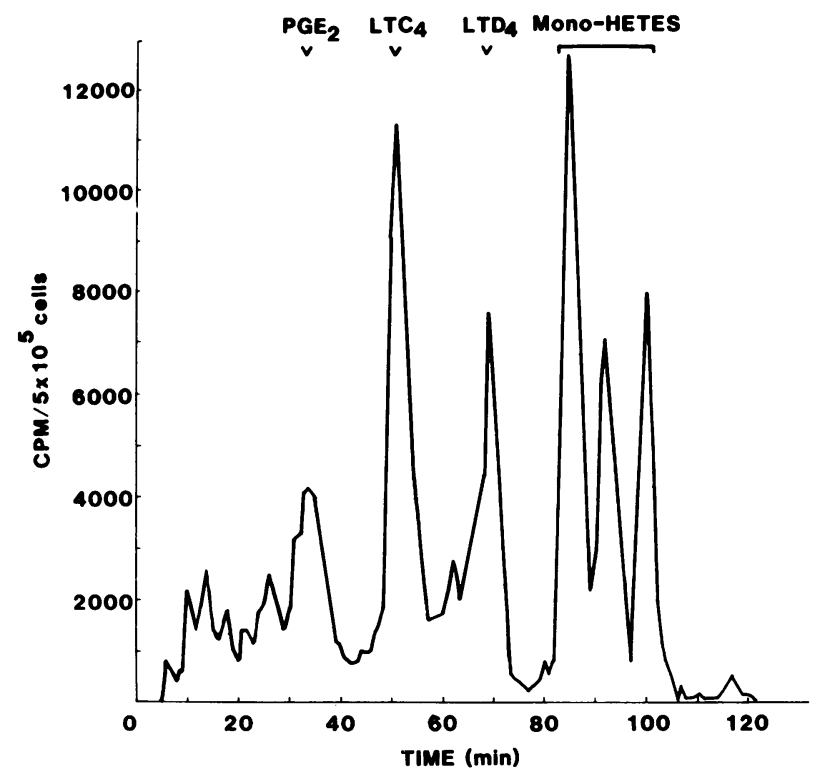

Figure 6. HPLC profile of AA metabolites that were synthesized by macrophages isolated from 8-d $S$. mansoni egg-induced pulmonary granulomas. The scan is a representative profile of three individual experiments. The column was equilibrated with the different standards as shown.

was observed at $50 \mu \mathrm{M}$, as $\mathrm{PGE}_{2}$ synthesis was reduced by $73 \%$ and LT by $90 \%$.

\section{Discussion}

The major impetus to examine the biochemical role of AA metabolites with regard to inflammation was provided by Vane

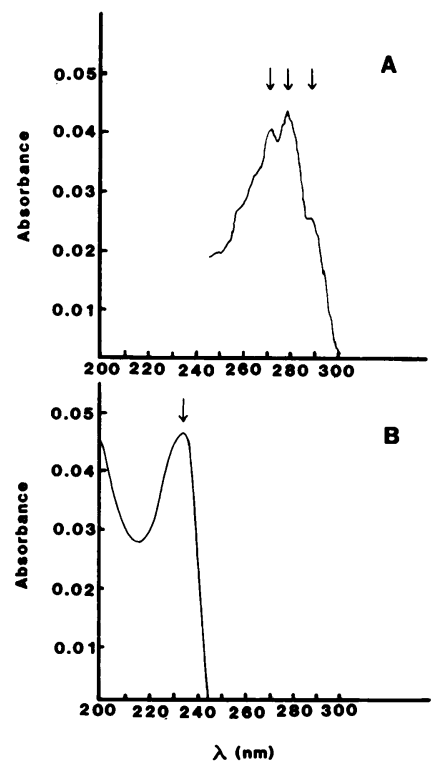

Figure 7. Ultraviolet spectra of extracts from pooled granuloma macrophage preparations eluting from the reverse-phase HPLC at 48-54 $\min (A)$, and at $82-88 \mathrm{~min}(B)$. The upper frame $(A)$ shows an ultraviolet spectrum characteristic of $\mathrm{LTC}_{4}$, with an absorbance maximum at $280 \mathrm{~nm}$ and shoulder absorbances at 270 and $292 \mathrm{~nm}$. The lower frame (B) shows a spectrum with a single peak at $235 \mathrm{~nm}$, which is characteristic of monoHETES.
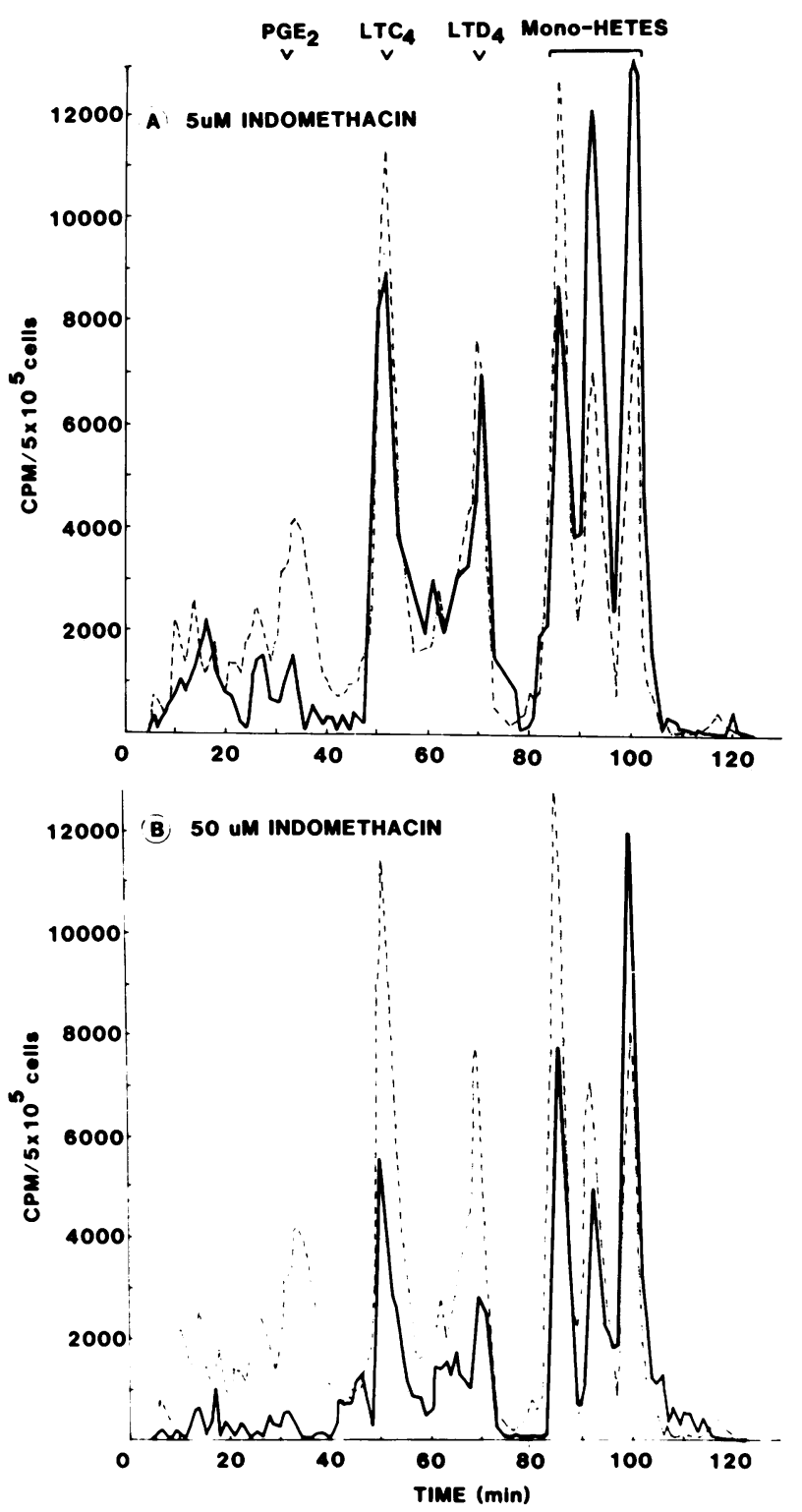

Figure 8. HPLC profiles of AA metabolites produced by 8-d schistosome egg granuloma macrophages that were treated with indomethacin. (ब) $5 \mu \mathrm{M}$ indomethacin, and (๑) $50 \mu \mathrm{M}$ indomethacin. Dashed line represents products of control cultures. The scan is a representative profile of three individual experiments. The number of viable, adherent macrophages per dish was identical among the groups.

(12) in 1971 with the observation that aspirin and aspirinlike drugs could suppress PG synthesis and control inflammation. Since that time, numerous similar nonsteroidal antiinflammatory drugs with anti-CO activity have been developed for the treatment of chronic inflammatory diseases such as rheumatoid arthritis. In addition, there was extensive basic research directed toward understanding the role of PGs in inflammation. Sur- 


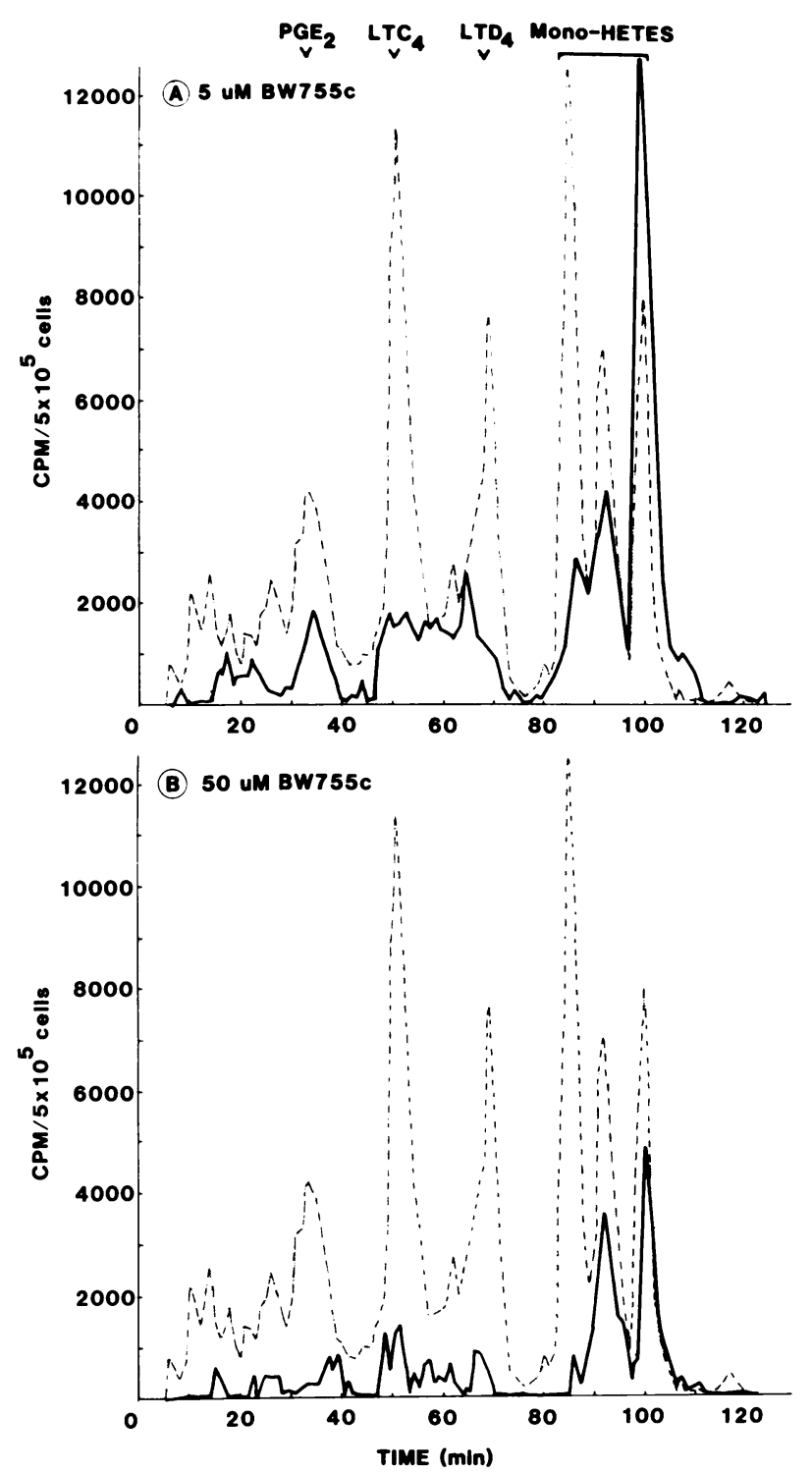

Figure 9. HPLC profile of AA metabolites produced by 8-d schistosome egg granuloma macrophages that were treated with BW755c. (ब) $5 \mu \mathrm{M}$ BW755c, and (๑) $50 \mu \mathrm{M}$ BW755c. Dashed line represents products of control cultures. The scan is a representative profile of three individual experiments. The number of viable, adherent macrophages per dish was identical among the groups.

prisingly, these $\mathrm{CO}$ derivatives seemed to be primarily involved in vasodilatory events, and in fact have been shown to have many antiinflammatory properties $(6-9,41)$. Recently, it has been shown that AA is metabolized by another class of enzymes, the lipoxygenases (1). The products generated by these pathways include the leukotrienes and the HETEs. Many of these products $\left(\mathrm{LTC}_{4}, \mathrm{LTB}_{4}, 5-\mathrm{HETE}\right)$ have been shown to have potent proinflammatory functions such as chemotaxis, vasodilation, and
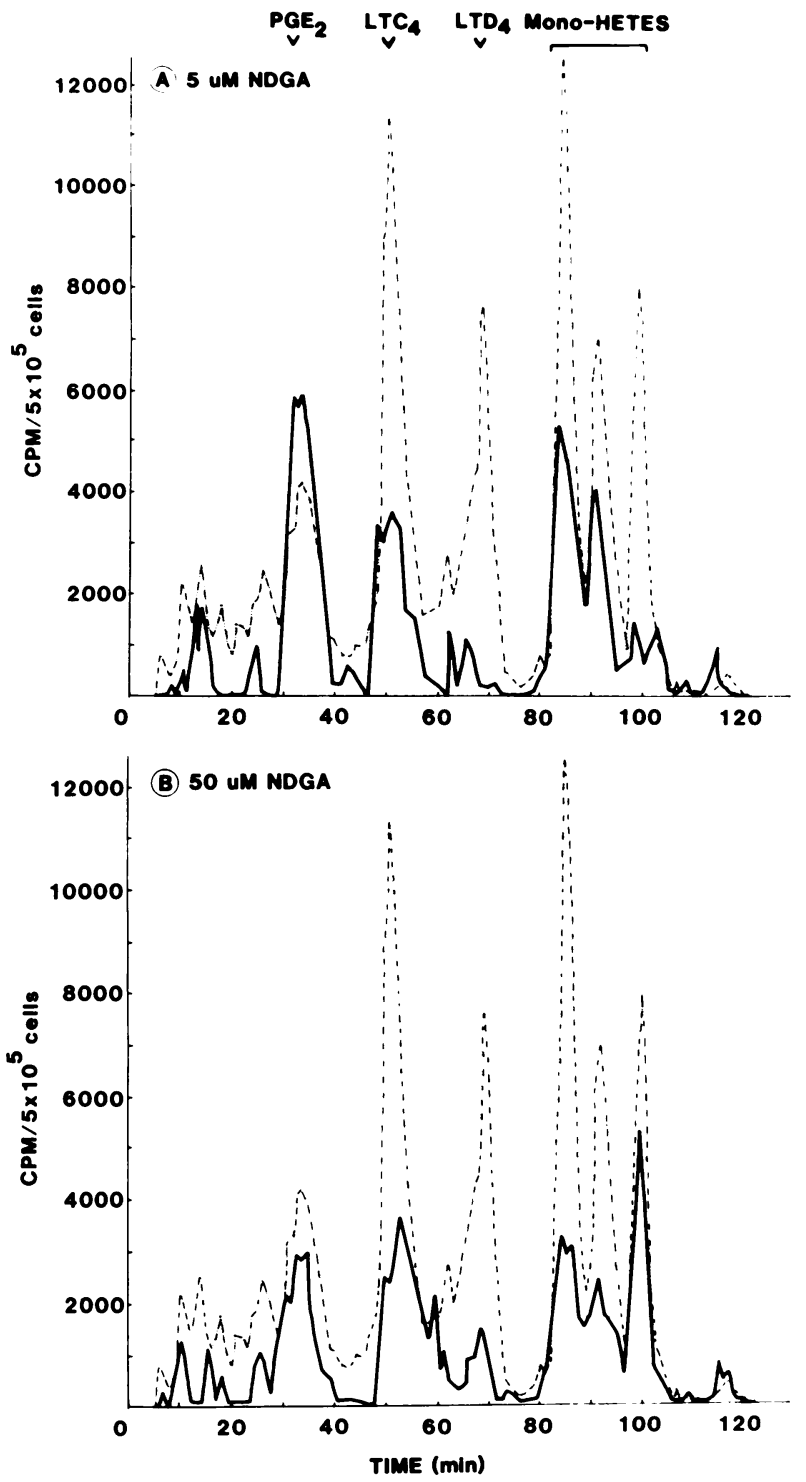

Figure 10. HPLC profile of AA metabolites produced by 8-d schistosome egg granuloma macrophages treated with NDGA. (ब( ) $5 \mu \mathrm{M}$ NDGA, and (ब) $50 \mu \mathrm{M}$ NDGA. Dashed line represents products of control cultures. The scan is a representative profile of three individual experiments. The number of viable, adherent macrophages per dish was identical among the groups.

induction of lysosomal enzyme release $(1,3,4)$. Thus, they have been implicated as important determinants in the inflammatory process. However, there is still a dearth of evidence that demonstrates their role in chronic inflammatory responses.

Using a variety of AA metabolic inhibitors, we attempted to determine the role of $\mathrm{CO}$ and $\mathrm{LO}$ products in the initiation and maintenance of hypersensitivity granulomas, which are induced by $S$. mansoni eggs. Those compounds (NDGA, BW755c, 


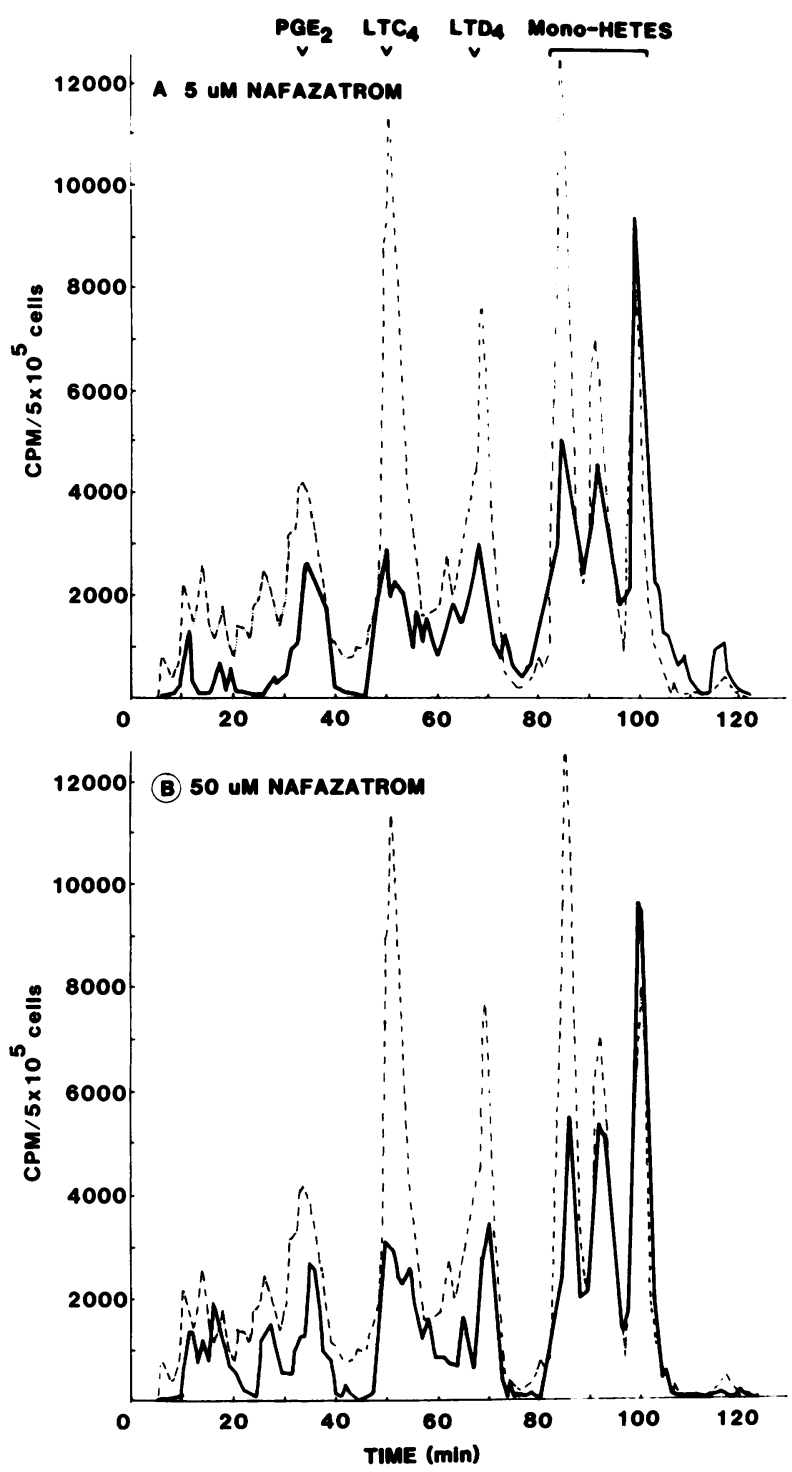

Figure 11. HPLC profile of AA metabolites produced by 8-d schistosome egg granuloma macrophages with nafazatrom. (囚) $5 \mu \mathrm{M}$ nafazatrom, and (๑) $50 \mu \mathrm{M}$ nafazatrom. Dashed line represents products of control cultures. The scan is a representative profile of three individual experiments. The number of viable, adherent macrophages per dish was identical among the groups.

and nafazatrom) putative anti-LO activity significantly suppressed both de novo and ongoing granuloma formation. In contrast, indomethacin, a selective $\mathrm{CO}$ antagonist, had no effect on granuloma formation at nontoxic doses. We have likewise tested another $\mathrm{CO}$ selective compound, ibuprofen, and it too had no significant effect on granuloma formation (data not shown).

Furthermore, by HPLC analysis we have demonstrated that $\mathrm{LTC}_{4}$ and 5-HETE were the major granuloma macrophage me- tabolites, which suggests not only that LO products may be produced at granulomatous foci but that macrophages are likely a major source of these biologically active lipids. At present there are but few reports that demonstrate the presence of LO products at sites of chronic inflammation. Klickstein et al. (42) have reported the recovery of $\mathrm{LTB}_{4}$ and 5-HETE from the synovia and synovial fluids of patients with rheumatoid arthritis and spondyloarthritis. Also, elevated levels of 12-HETE have been described in the epidermis of psoriatic lesions (43). Our studies corroborate and extend these preliminary observations and provide direct evidence that macrophages that are isolated from immune hypersensitivity granulomas are capable of metabolizing AA to LO products that may potentially sustain the tissue reaction.

Also, by HPLC analysis of recovered metabolites, we delineated the selectivity of the various inhibitory compounds on granuloma macrophage AA metabolism. Our findings are in general agreement with previous reports, which have shown indomethacin to have the greatest CO selectivity and NDGA to be LO specific (44). Overall, BW755c and nafazatrom were nonselective, but the 5-lipoxygenase appeared to be more sensitive to these agents then the other LOs. It is important to note that at the higher concentration $(50 \mu \mathrm{M})$, all of the compounds showed a loss of selectivity. This loss of selectivity may in part explain the suppressive effect of toxic doses $(10 \mathrm{mg} / \mathrm{kg})$ of indomethacin on granuloma formation in vivo. Interestingly, at lower doses, indomethacin appeared to induce substrate shunting, augmenting mono-HETEs while suppressing PG synthesis. This observation corroborates the findings of Scott et al. (44) and Van Rollins et al. (33), who also showed that indomethacin can amplify mono-HETE synthesis in macrophages and platelets, respectively. An attempt to directly examine AA metabolism by granuloma macrophages that were isolated from mice treated in vivo was less informative, since many of the compounds are reversible inhibitors of the AA metabolic enzymes.

Our finding that AA metabolic inhibitors can dramatically alter granuloma macrophage Ia antigen expression suggests another mechanism, whereby these inhibitors can modulate granuloma formation, and lends support to the current notion that AA metabolites may regulate macrophage Ia antigen expression. Animals administered $5 \mathrm{mg} / \mathrm{kg}$ indomethacin daily showed a clear potentiation of granuloma macrophage Ia antigen expression. This is in complete accord with several independent studies which used splenic or peritoneal macrophage populations (17, $18,45)$. Thus, as previously suggested, $C O$ products such as $\mathrm{PGE}_{2}$ may statically inhibit macrophage Ia expression as an autoregulatory phenomenon and thereby, indirectly, regulate $T$ cell-macrophage interaction (18). This concept is supported by our recent report that describes the suppression of granuloma size and granuloma macrophage Ia expression by parenterally administered PGE (39). It can also explain the capacity of indomethacin to potentiate mixed lymphocyte reactions (46), mitogen responses (47), and cytotoxic effector cell generation (48), all of which require the participation of Ia-positive macrophages. Interestingly, by administering agents with anti-LO activity, we 
found the opposite effect, which was suppression of Ia expression. By day 16 the size of granulomas and the percentage of Iapositive granuloma macrophages in animals that were treated with LO inhibitors was reduced by $50-60 \%$. It is a reasonable speculation that macrophage Ia expression that is induced by T cell-derived lymphokines may be suppressed by LO inhibitors that limit T-lymphocyte functions. Several in vitro investigations have shown that LO inhibitors can suppress cell-mediated immune mechanisms. For example, NDGA has been shown to inhibit mitogen-induced blastogenesis by human peripheral blood lymphocytes (22), as well as to reduce murine effector $\mathrm{T}$ cell cytotoxicity and proliferation (25). Moreover, inhibitors of the LO pathway have also been reported to suppress both mitogen and antigen-specific lymphocyte proliferation $(49,50)$. Recently Rand et al. (51) have demonstrated that certain classes of mono-HETEs can augment lymphokine activity, and that this response was suppressed by inhibitors of LO. Taken together, the above findings suggest that there is an antagonistic relationship between $\mathrm{CO}$ and LO pathway products. In general, the LO products appear to be proinflammatory and the $\mathrm{CO}$ products antiinflammatory.

In conclusion, the present study supports the hypothesis that AA metabolites of LO pathway are important inflammatory mediators. Furthermore, these products appear to participate in the initiation and maintenance of chronic hypersensitivity granuloma formation. The development of more specific enzyme antagonists will likely help to further elucidate the participation of various AA metabolites in chronic inflammation, as well as provide effective therapeutic tools.

\section{Acknowledgments}

The authors wish to express their appreciation for the expert secretarial assistance of Jeny Breakstone. This work was supported in part by National Institutes of Health grants HL 31237, HL 31963, and AM 20572.

\section{References}

1. Samuelsson, B. 1982. The leukotrienes: an introduction. In Leukotrienes and Other Lipoxygenase Products. B. Samuelsson and R. Paoletti, editors. Raven Press, New York. 1-17.

2. Bailey, J. M., R. W. Bryant, C. E. Low, M. B. Pupillo, and J. Y. Vanderhoek. 1982. Regulation of T-lymphocyte mitogenesis by the leukocyte product 15-hydroxy-eicosatetraenoic acid (15-HETE). Cell. Immunol. 67:112-120.

3. Ford-Hutchinson, A. W., M. A. Bray, M. V. Doig, M. E. Shipley, and M. J. Smith. 1980. Leukotriene B, a potent chemokinetic and aggregating substance released from polymorphonuclear leukocytes. Nature (Lond.). 286:264.

4. O'Flaherty, J. T., M. J. Thomas, C. J. Lees, and C. E. McCall. 1981. Neutrophil-aggregating activity of monohydroxyeicosatetraenoic acids. Am. J. Pathol. 104:55-62.

5. Koren, H. S., S. J. Anderson, D. G. Fischer, C. S. Copeland, and P. J. Jensen. 1981. Regulation of human natural killing. I. The role of monocytes, interferon, and prostaglandins. J. Immunol. 127:2007-2013.

6. Gordon, D., M. A. Bray, and J. Morley. 1976. Control of lymphokine secretion by prostaglandins. Nature (Lond.). 262:401-402.
7. Kunkel, S. L., R. S. Thrall, R. G. Kunkel, P. A. Ward, and R. B. Zurier. 1979. Suppression of immune complex vasculitis by prostaglandin. J. Clin. Invest. 64:1525-1529.

8. Chensue, S. W., S. L. Kunkel, P. A. Ward, and G. I. Higashi. 1983. Exogenously administered prostaglandins modulate pulmonary granulomas induced by Schistosoma mansoni eggs. Am. J. Pathol. 111:78-87.

9. Kunkel, S. L., J. C. Fantone, P. A. Ward, and R. B. Zurier. 1981. Modulation of inflammatory reactions by prostaglandins. Prog. Lipid Res. 20:633-640.

10. Mertin, J., and A. Stackpool. 1981. Prostaglandin precursors and the cell mediated immune response. Cell. Immunol. 62:293-300.

11. Ohuchi, K., A. Sato, and S. Tsurufuji. 1976. The content of prostaglandin $\mathrm{E}$ and prostaglandin $\mathrm{F}_{2 \alpha}$ in the exudate of carrageenin granuloma of rats. Biochim. Biophys. Acta. 424:239-448.

12. Vane, J. R. 1971. Inhibition of prostaglandin synthesis as a mechanism of action for aspirin-like drugs. Nature (Lond.). 231:232235 .

13. Goetz, J. M., H. Sprecher, D. G. Cornwell, and R. V. Paganamala. 1976. Inhibition of prostaglandin biosynthesis by triynoid acids. Prostaglandins. 12:187-192.

14. Orning, L., and S. Hammarstrom. 1980. Inhibition of leukotriene C and leukotriene D biosynthesis. J. Biol. Chem. 255:8023-8026.

15. Kemp, J., D. Louie, J. Mattingly, J. Bennett, C. Higuchi, J. Pretell, M. Horowitz, and R. Gershon. 1980. Suppressor cells in vitro: differential effects of indomethacin and related compounds. J. Immunopharmacol. 2:471-489.

16. Higgs, G. A., R. J. Flower, and J. R. Vane. 1979. A new approach to antiinflammatory drugs. Biochem. Pharmacol. 28:1959-1961.

17. Steeg, P. S., H. M. Johnson, and J. J. Oppenheim. 1982. Regulation of murine macrophage Ia antigen expression by an immune interferon-like lymphokine: inhibitory effect of endotoxin. J. Immunol. 129:2402-2406.

18. Snyder, D. S., C. Y. Lu, and E. R. Unanue. 1982. Control of macrophage Ia expression in neonatal mice-role of a splenic suppressor cell. J. Immunol. 128:1458-1465.

19. Smolen, J. E., and G. Weissman. 1980. Effects of indomethacin, 5,8,11,14-eicosatetraenoic acid, and P-bromophenacyl bromide on lysosomal enzyme release and superoxide anion generation by human polymorphonuclear leukocytes. Biochem. Pharmacol. 29:533-538.

20. Higgs, G. A., K. E. Eakine, K. G. Mugridge, S. Moncada, and J. R. Vane. 1980. The effects of non-steroid anti-inflammatory drugs on leukocyte migration in carrageenin-induced inflammation. Eur. $J$. Pharmacol. 66:81-86.

21. Needleman, P., B. Bryan, A. Wyche, S. D. Bronson, K. Eakens, J. A. Ferrendelli, and M. Minkes. 1977. Thromboxane synthetase inhibitors as pharmacological tools: differential biochemical and biological effects on platelet suspensions. Prostaglandins. 13:897-902.

22. Kelly, J. P., M. C. Johnson, and C. W. Parker. 1979. Effects of inhibitors of arachidonic acid metabolism on mitogenesis in human lymphocytes: possible role of thromboxanes and products of the lipoxygenase pathway. J. Immunol. 122:1563-1570.

23. Crout, J. E., B. Hepburn, and R. E. Ritts. 1975. Suppression of lymphocyte transformation after aspirin ingestion. N. Engl. J. Med. 292:221-225.

24. Panayi, G. S., and A. Rix. 1974. The effect of phenylbutazone, indomethacin, and ibuprofen on lymphocyte stimulation by phytohemagglutinin in vitro. Rheumatol. Rehabil. 13:179-184.

25. Leung, K. H., M. J. Ehrke, and E. Mihich. 1982. Modulation of the development of cell-mediated immunity: possible role of the 
products of the cyclooxygenase and the lipoxygenase pathways of arachidonic acid metabolism. Int. J. Immunopharmacol. 4:195-204.

26. Chensue, S. W., S. R. Wellhausen, and D. L. Boros. 1981. Modulation of granulomatous hypersensitivity: II. Participation of Ly $1+$ and Ly2 + lymphocytes in the suppression of granuloma formation and lymphokine production in Schistosoma mansoni-infected mice. J. Immunol. 127:363-367.

27. Coker, C. M., and F. Von Lichtenberg. 1956. Revised method for isolation of Schistosoma mansoni eggs for biological experimentation. Proc. Soc. Exp. Biol. Med. 92:359-364.

28. Oi, V. T., P. P. Jones, J. W. Goding, L. A. Herzenberg, and L. A. Herzenberg. 1978. Properties of monoclonal antibodies to mouse Ig allotypes, H-2 and Ia antigens. In Current Topics in Microbiology and Immunology. F. Melchers, M. Potter, and N. Warner, editors. Springer-Verlag New York Inc. 81:115-129.

29. Ozato, K., and D. H. Sachs. 1981. Monoclonal antibody to mouse MHC antigens. III. Hybridoma antibodies reacting to antigens of the $\mathbf{H}-2^{b}$ haplotype reveal genetic control of isotype expression. $J$. Immunol. 126:317-321.

30. Beller, D. I., and E. R. Unanue. 1980. Ia antigens and antigenpresenting function of thymic macrophages. J. Immunol. 124:14331440.

31. Moore, D. L., D. I. Grove, and K. S. Warren. 1977. The Schistosoma mansoni egg granuloma: quantitation of cell populations. $J$. Pathol. 121:41-50.

32. Amsden, A. F., and D. L. Boros. 1979. Fc-receptor-bearing macrophages isolated from hypersensitivity and foreign body granulomas. Delineation of macrophage dynamics, $\mathrm{Fc}$ receptor density/avidity and specificity. Am. J. Pathol. 96:457-473.

33. Van Rollins, M., S. H. K. Ho, J. E. Greenwald, M. Alexander, N. J. Dorman, L. K. Wong, and L. A. Horrochs. 1980. Complete separation by high performance liquid chromatography of metabolites of arachidonic acid from incubation with human and rabbit platelets. Prostaglandins. 20:571-577.

34. Rouzer, C. A., W. A. Scott, A. L. Hamill, F. Liu, D. N. Katz, and Z. A. Cohn. 1982. Secretion of Leukotriene $C$ and other arachidonic acid metabolites by macrophages challenged with immunoglobulin $\mathrm{E}$ immune complexes. J. Exp. Med. 156:1077-1086.

35. Hamberg, M., and B. Samuelsson. 1967. On the specificity of the oxygenation of unsaturated fatty acids catalyzed by soybean lipoxyidase. J. Biol. Chem. 242:5329-5335.

36. Unanue, E. R. 1981. The regulatory role of macrophages in antigenic stimulation: symbiotic relationship between lymphocytes and macrophages. Adv. Immunol. 31(Pt. 2):1-136.

37. Stadecker, M. J., D. J. Wyler, and J. A. Wright. 1982. Ia antigen expression and antigen-presenting function by macrophages isolated from hypersensitivity granulomas. J. Immunol. 128:2739-2744.
38. Snyder, D. S., D. I. Beller, and E. R. Unanue. 1982. Prostaglandins modulate macrophage Ia expression. Nature (Lond.). 299:163-165.

39. Kunkel, S. L., S. W. Chensue, M. C. Plewa, and G. I. Higashi. 1984. Macrophage function in the Schistosoma mansoni egg induced pulmonary granuloma: role of arachidonic acid metabolites in macrophage Ia antigen expression. Am. J. Pathol. 114:240-249.

40. Murphy, R. C., S. Hammarstrom, and B. Samuelsson. 1979. Leukotriene C: a slow-reacting substance from murine mastocytoma cells. Proc. Natl. Acad. Sci. USA. 79:4275-4281.

41. Kunkel, S. L., and S. W. Chensue. 1983. Prostaglandins and the regulation of immune responses. Adv. Inflammation Res. 7:93-109.

42. Klickstein, L. B., C. Shapleigh, and E. Goetzl. 1980. Lipoxygenation of arachidonic acid as a source of polymorphonuclear leukocyte factors in synovial fluid and tissue in rheumatoid arthritis and spondyloarthritis. J. Clin. Invest. 66:1166-1176.

43. Hammarstrom, S., M. Hamberg, B. Samuelsson, E. A. Duell, M. Stawish, and J. J. Voorhees. 1975. Increased concentration of nonesterified arachidonic acid, 12L-hydroxy-5,8,10,14 eicosatetraenoic acid, prostaglandin $\mathrm{E}_{2}$ and prostaglandin $\mathrm{F}_{2 \alpha}$ in the epidermis of psoriasis. Proc. Natl. Acad. Sci. USA. 72:5130-5134.

44. Scott, W. A., N. A. Pawlowski, M. Andreach, and Z. A. Cohn. 1982. Resting macrophages produce distinct metabolites from exogenous arachidonic acid. J. Exp. Med. 155:535-547.

45. Piguet, P. F., C. Irle, and P. Vassalli. 1981. Immuno-suppressor cells from newborn mouse spleen are macrophages different in vitro from monoblastic precursors. Eur. J. Immunol. 11:56-61.

46. Darrow, T. L., and R. H. Tomar. 1980. Prostaglandin-mediated regulation of the mixed lymphocyte culture and generation of cytotoxic cells. Cell. Immunol. 56:172-183.

47. Goodwin, J. S., and D. R. Webb. 1980. Regulation of the immune response by prostaglandins. Clin. Immunol. Immunopathol. 15:106122.

48. Lueng, K. H., and E. Mihich. 1981. Effects of prostaglandins on cell-mediated immunity in culture and on the cytolytic activity of in vivo-generated effector cells. Int. J. Immunopharmacol. 4:205-217.

49. Williams, R. O., and L. A. Loeb. 1973. Zinc requirement for DNA replication in stimulated human lymphocytes. J. Cell Biol. 58:594601.

50. Archer, D. L., B. G. Smith, and J. A. Bukovic-Wess. 1976. Gallic acid: a potential chemical tool for studying cellular interactions involved in the in vitro immune response. IRCS (Int. Res. Commun. Syst.) Med. Sci. Libr. Compend. 4:553-556.

51. Rand, T. H., J. Turk, R. L. Mass, and D. G. Colley. 1982. Arachidonic acid metabolism of the murine eosinophil. II. Involvement of the lipoxygenase pathway in the response to the lymphokine eosinophil stimulating promoter. J. Immunol. 129:1239-1244. 